\title{
BMJ Open Biomechanical and organisational constraints of pregnant women at work: definition of exposure levels using a consensus method (Delphi)
}

\author{
Thomas Certenais (D) , ",2 Raphaëlle Teysseire, ${ }^{2,3}$ Ronan Garlantezec, ${ }^{4}$ \\ Patrick Brochard, ${ }^{2,3}$ Guyguy Manangama, ${ }^{2,3}$ Fleur Delva (D) ${ }^{2,3}$
}

To cite: Certenais T, Teysseire R, Garlantezec R, et al. Biomechanical and organisational constraints of pregnant women at work: definition of exposure levels using a consensus method (Delphi). BMJ Open 2022;12:e052474. doi:10.1136/ bmjopen-2021-052474

- Prepublication history and additional supplemental material for this paper are available online. To view these files, please visit the journal online (http://dx.doi.org/10.1136/ bmjopen-2021-052474)

Received 01 June 2021 Accepted 05 February 2022
Check for updates

(C) Author(s) (or their employer(s)) 2022. Re-use permitted under CC BY-NC. No commercial re-use. See rights and permissions. Published by BMJ.

For numbered affiliations see end of article.

Correspondence to Dr Thomas Certenais; thomas.certenais@gmail.com

\section{ABSTRACT}

Objectives To identify the biomechanical and organisational constraints that influence pregnancy outcomes and define the exposure levels at which the risks for pregnancy become significant.

Setting and participants We applied a consensus method (Delphi) consisting of a literature review followed by expert opinions on exposure levels. The group of experts was made up of 12 people from different medical specialities and working in various structures in France. Outcome measures The studied variables were: (1) exposure: night work/shift work, weekly hours at work, lifting of heavy loads, prolonged standing and multiple exposure and (2) pregnancy outcomes: prematurity, low birth weight and spontaneous miscarriages.

Results The consensus method resulted in the following recommendations. The time spent working must not exceed 40 hours/week; in the absence of a consensus on the level of exposure, night and/or shift work must be avoided; prolonged standing must not exceed 3 hours/ day; lifting must be limited to carrying loads $<11 \mathrm{~kg}$, with a daily load $<100 \mathrm{~kg}$; multiple exposure must be avoided, in particular: vibration, night work/shift work, time spent working exceeding 40 hours/week, prolonged standing and lifting of heavy loads.

Conclusions These results could help the occupational physician to address the question of whether an exposed employee should remain at work, considering her individual characteristics (medical history, family situation, socioeconomic level, etc) in consultation with pregnancy specialists (obstetricians, midwives).

\section{INTRODUCTION}

In most parts of the world, many women work during the pregnancy. ${ }^{1}$ Certain workplaces may expose women to known or suspected reproductive hazards. ${ }^{2-7}$ The occupational exposure most frequently found among women seen for pathological pregnancies at the Environmental Health Platform Dedicated to Reproduction of Bordeaux University Hospital (France) in $2019^{8}$ were biomechanical $(32.3 \%)$ and organisational constraints $(6.3 \%),{ }^{9}$ for which the scientific
Strengths and limitations of this study

- Consensus method (Delphi method) was based on a group of twelve French experts from different specialities (in the fields of occupational health and perinatal health) and centres of expertise.

- A literature review was conducted and submitted to this group of experts before their participation in the Delphi.

- The scope of the study is limited to first physiological pregnancies with a singleton and in the absence of a gynaecological-obstetrical history.

- Each constraint was assessed separately, keeping in mind the complex notion of the interaction between multiple types of exposure.

literature shows a low to moderate excess risk for pregnancy. $12410-13$

In 2009, the Royal College of Physicians (RCP) highlighted the variability in the practices of preventive physicians in the National Health Service in terms of risk assessment and decision making for adapting the work or taking a leave of absence. American and Danish studies reported similar variability. ${ }^{14}$ The RCP specified that such variability is partially due to the lack of clarity in the guidelines used (and sometimes even to the lack of guidelines), the recommendations of which are sometimes difficult to apply in the field. This results in difficulties in assessing the professional situations that put pregnant women at risk and therefore in variable and 'dependent professional' practices. Most studies concerning biomechanical and organisational constraints highlight difficulties in assessing exposure and defining exposure thresholds above which the risk becomes significant, $^{2411}$ mainly because of a lack of homogeneity in the definitions of exposure and thresholds in the available studies. ${ }^{14}$ We applied a Delphi consensus method to 
summarise expert opinion to overcome such limitations, addressing this issue by seeking expert opinion to complete the literature data.

The objectives of this study were to identify the biomechanical and organisational constraints that affect pregnancy outcomes and define the exposure levels at which risks to pregnancy become significant using a consensus method (Delphi).

\section{METHODS}

\section{Selection of constraints and pregnancy outcomes}

The French expert opinion 'Pregnancy and Work', ${ }^{15}$ published in 2010 by the French National Research and Safety Institute for the Prevention of Occupational Accidents and Diseases, is a reference in the field of French occupational health. It enabled us to define the constraints of interest for this study. For biomechanical constraints, we chose prolonged standing and heavy load carrying; for organisational constraints, we studied night work, shift work and the amount of time spent working per week. We selected the following pregnancy outcomes: spontaneous miscarriage, premature birth and intrauterine growth retardation (low birth weight and low weight for gestational age).

\section{Delphi method}

The Delphi method is a consensus method. ${ }^{16} 17$ Our approach consisted of two parts: (1) a literature review to identify the available data on the relationship between biomechanical and organisational constraints in the workplace and their effect on pregnancy outcomes and (2) an expert opinion by sending out a questionnaire based on data from the literature review (data provided to experts) to identify the constraints that influence pregnancy outcomes and define the levels of exposure at which the risks for pregnancy become significant.

\section{Literature review}

Data selection

The literature review consisted of two steps: The first consisted of a search for recommendations from institutional sources (eg, the French National Public Health Agency and the French National Authority for Health, the NIOSH, the NICE, the NIH ...). For this step, we conducted a search of the grey literature in the search engines of websites of institutions related to occupational health or obstetrics (online supplemental file 1) using the key words: 'pregnancy', 'work', 'employment'. The search was conducted in both English and French. The recommendations had to target working conditions for pregnant women, be written in English or French, and to have been published less than 20 years ago. The second step consisted of the search for scientific articles published since the date of publication of the recommendations to complete the review with data not covered in the recommendations. For this step, we conducted a search in two databases, Medline and Scopus, using the following keywords: 'work schedule tolerance', 'shift work schedule', 'working hours', 'posture', 'lifting', 'pregnancy'. The publications analysed had to be reviews or original articles. For each constraint studied, articles published from the date of publication of the corresponding recommendations were selected, first reviews or meta-analyses and then original articles not cited in the first selection. The original published studies had to be analytical epidemiological studies, consisting of cohort or case-control studies. The target population had to be women who had been employed during pregnancy, without selection of the sector of activity or geographical origin. The articles had to be written in English or French and those not providing detailed results were excluded.

\section{Data extraction and presentation of the results}

Each constraint was treated separately. No meta-analysis or statistical analysis was done. Data were compiled and summarised in tabular and forest-plot form: method of determining exposure and constraints, confounding factors, main results, etc. These data were made available to the experts.

\section{Selection of experts}

This French expert group was set up based on the criteria of competence (diversity of medical specialties, knowledge of the subject, academic profile, field experience) and availability (time needed to answer the questionnaires). Among 17 experts contacted by email, 13 agreed to participate. The first questionnaire was sent by email on 4 December 2019 and the second on 11 February 11, 2020. Ten experts (five occupational physicians, one obstetrician-gynaecologist, two midwives/epidemiologist, two public health physicians/epidemiologist) replied to both questionnaires, one expert (occupational physician) replied only to the first questionnaire and another (obstetrician-gynaecologist) only to the second.

\section{Synthesis for the experts}

\section{Preparation of questionnaires}

We divided the questionnaire (online supplemental file 2) into four parts, corresponding to the four constraints studied. For each constraint, we asked the experts to: (1) qualitatively estimate the probability of association between the constraint and pregnancy outcome: no association detected, possible association, probable association, definite association; (2) quantitatively estimate the level of exposure at which the risk becomes significant in their opinion using levels of exposure based on those presented by the studies included in the literature review and (3) add remarks related to the questionnaires in a comment space.

\section{Experts involvement}

The experts were partly involved in the design of this study: comments on the first questionnaire helped to refine the second questionnaire. The main results have been disseminated to the experts and we will seek their participation to disseminate these data appropriately. 
Final synthesis of the results

We retained only 'consensual' responses for the final synthesis. We considered a response to be 'consensual' if one of the proposed items received more than half the number of responses $(>50 \%) .{ }^{16}$ The questions that received a 'consensual' response in the first round were systematically repeated in the second round.

Patient and public involvement

No patient involved.

\section{RESULTS}

\section{Literature review}

All the data from the literature review are presented in online supplemental files 3 and 4 (flow chart, tables and forest plot syntheses). For each constraint, 3-9 meta-analyses were cited and synthesised (in addition to a varying number of original articles not cited in the meta-analyses).

Most studies concerning nightwork simply assessed the number of nights worked during all or part of the pregnancy. In the studies on the effect of night work on the risk of premature delivery, Specht et al ${ }^{18}$ discriminated between the number of consecutive nights and the total number of nights per trimester when assessing exposure. We included this distinction in our questionnaire. Concerning the carrying of heavy loads, the assessment of exposure differed depending on the study: some assessed exposure by carrying a unit load, others by combining the weight of the load and the frequency of lifting, and still others based on the accumulated weight over 1 day (without specifying the unit load or the frequency of lifting). In our questionnaire, we presented two items in the choice of exposure level: the unit load and the cumulative load over 1 day. For all other constraints, the questionnaire contained only one possible way of assessing exposure, with several levels to choose from.

\section{Delphi expert opinion}

The answers of the experts to the second questionnaire are presented in table 1 . All experts responded to the first part of the questionnaire about the level of association. None chose the 'definite association' classification. Consensus was reached on all issues except for the association between heavy lifting and low birth weight. Although several experts did not comment on the level of exposure, consensus was reached on all issues except night work. A synthesis of the results of this consensus method is presented in table 2. Each of the types of exposure was considered to be 'probably associated' with at least one of the pregnancy complications and prolonged standing and heavy lifting were associated with two pregnancy outcomes (preterm delivery and spontaneous miscarriage). Preterm delivery and spontaneous miscarriage were considered to be 'probably associated' with three of the constraints but low birth weight did not reach the level of probable association.

\section{DISCUSSION}

\section{Interpretation of results and implications for clinical practice}

Each of the types of exposure was considered to be 'probably associated' with at least one of the pregnancy complications (prolonged standing and heavy lifting were associated with two pregnancy outcomes). This result confirms the importance of the occupational physician considering each of these types of exposure in the assessment of risk for pregnancy.

In summary and for clinical practice, we propose the following recommendations for the pregnant employee:

- The time spent working should not exceed 40 hours per week.

- In the absence of a consensus on the level of exposure, night and/or shift work should be avoided.

- Prolonged standing should not exceed 3 hours per day.

- Heavy lifting should be limited to $11 \mathrm{~kg}$ and a daily load $<100 \mathrm{~kg}$.

The impact of such exposure on pregnancy probably varies with the term of the pregnancy and makes it difficult to propose exposure thresholds based on the period. In the absence of strong evidence concerning this issue, we recommend that these limits be applied from the beginning of the pregnancy as a precautionary measure.

It is important to note that these opinions are valid in the case of a first physiological pregnancy with a singleton and in the absence of a gynaecological-obstetrical history, as most of the studies selected were based on these criteria. These recommendations should be adapted and individualised according to the risk factors and personal history of each woman (in consultation with the other healthcare professionals involved: obstetrician, midwife, general practitioner, etc). They should be considered with caution by the occupational physician and serve as a reference point in addressing whether an exposed employee should continue doing the same job.

\section{Contributions of the scientific literature}

Although the causal links between occupational exposure and perinatal health have not always been clearly established, there is evidence for a certain level of biological plausibility for the associations between these factors. Three physiological mechanisms are often cited: (1) alteration of uterine perfusion due to postural constraints (such as prolonged standing or heavy lifting), (2) activation of the hypothalamic-pituitary axis and (3) increased catecholamine production through chronic activation of the sympathetic nervous system. Variations in the concentration of a number of hormones or neurotransmitters lead to an increase in uterine contractility and a decrease in uterine and placental perfusion, which are responsible for a decrease in the supply of oxygen and nutrients to the fetus and thus an alteration in fetal growth. Decreased placental function is accompanied by decreased production of progesterone and increased synthesis of corticotropin-releasing hormone (CRH), responsible for an increase in the release of prostaglandins 
Table 1 Results of the second round of the consensus method

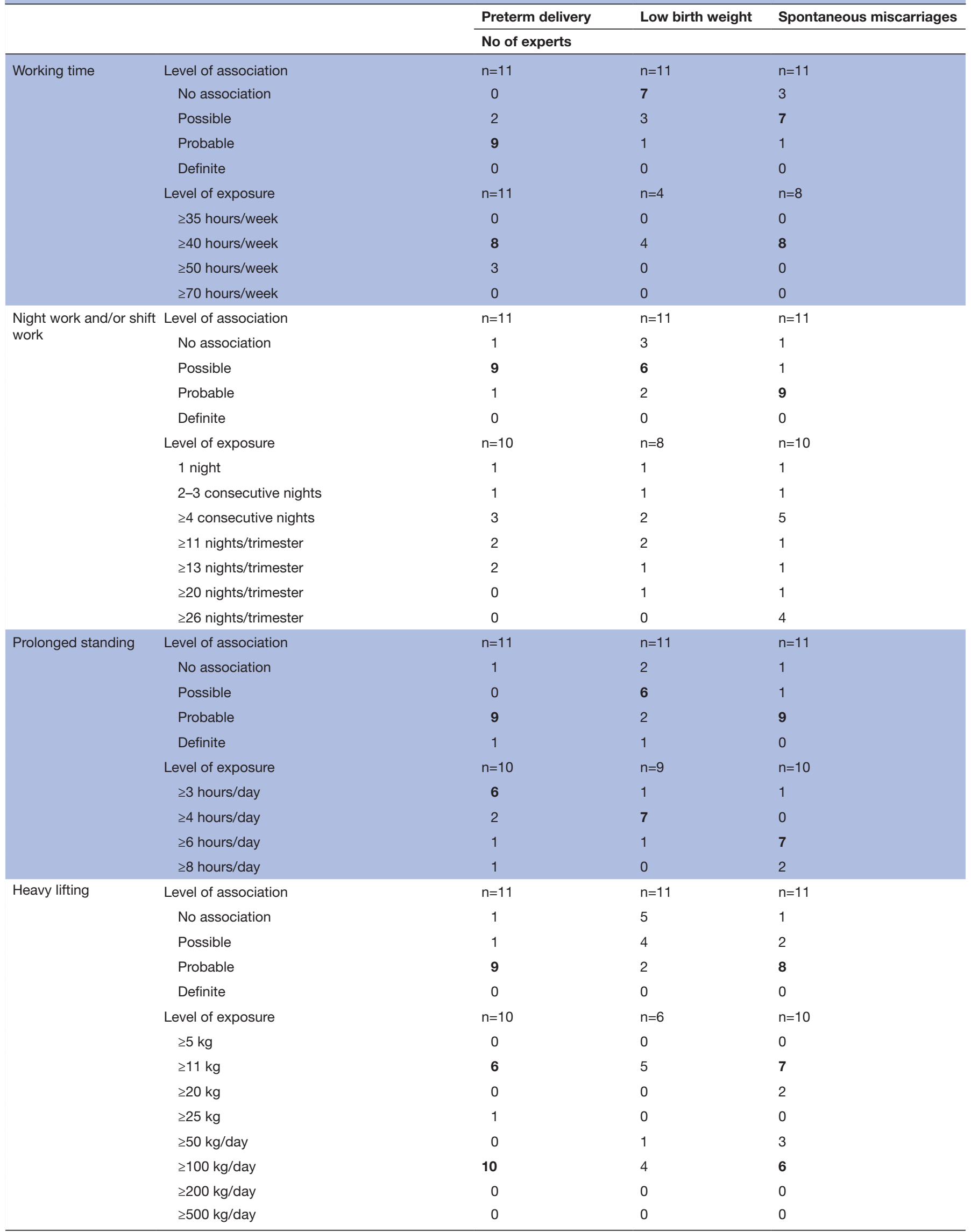

Bold values correspond to items that received more than half of the responses. 
Table 2 Synthesis of the results from the consensus method

\begin{tabular}{|c|c|c|c|}
\hline & Preterm delivery & Low birth weight & Spontaneous miscarriages \\
\hline Work time & $\begin{array}{l}\text { Association: probable } \\
\geq 40 \text { hours/week }\end{array}$ & Association: none & $\begin{array}{l}\text { Association: possible } \\
\geq 40 \text { hours/week }\end{array}$ \\
\hline Prolonged standing & $\begin{array}{l}\text { Association: probable } \\
\geq 3 \text { hours/day }\end{array}$ & $\begin{array}{l}\text { Association: possible } \\
\geq 4 \text { hours/day }\end{array}$ & $\begin{array}{l}\text { Association: probable } \\
\geq 6 \text { hours/day }\end{array}$ \\
\hline Heavy lifting & $\begin{array}{l}\text { Association: probable } \\
\text { single load } \geq 11 \mathrm{~kg} \\
\text { daily load } \geq 100 \mathrm{~kg}\end{array}$ & $\begin{array}{l}\text { No consensus about the level } \\
\text { of association }\end{array}$ & $\begin{array}{l}\text { Association: probable } \\
\text { - single load } \geq 11 \mathrm{~kg} \\
\text { - daily load } \geq 100 \mathrm{~kg}\end{array}$ \\
\hline
\end{tabular}

Items received more than half the number of responses (> 50\%).

and oxytocin. These hormones, which are involved in the induction of obstetric labour, associated with increased uterine contractility, can lead to premature labour. ${ }^{19-21}$ Night work also involves disruption of the original circadian rhythm and changes in the concentrations of certain maternal hormones involved in pregnancy and fetal development (melatonin). ${ }^{22-26}$

\section{Strengths and weaknesses}

Risk-based approach

We chose a risk-based approach for which the conclusions can be applied to any workstation, keeping in mind the complex notion of the interaction between multiple types of exposure. The main limitation of the occupation-based approach is the simultaneous consideration of sometimes numerous and variable types and levels of exposure, making it difficult to assess the individual impact of each type of exposure on the health effect studied. ${ }^{15}$

\section{Literature review}

Three to nine meta-analyses were cited and synthesised, thus providing the experts with a satisfactory volume of quality data to help them in their reflection.

Many experts expressed difficulties in the analysis of the literature data. In addition to the intrinsic quality of the proposed studies, they highlighted the interstudy heterogeneity of the data presented: heterogeneity of the patient samples (age, parity, employment, etc), the definitions of pregnancy outcomes and constraints, the methods for evaluating or measuring exposures, the confounding factors considered, etc. Such heterogeneity makes it difficult to produce a quality synthesis. The choice of a consensus method was motivated by this observation. The Delphi method is a subjective method, allowing the addition of the intuition and knowledge of experts to the data in the literature.

\section{Consensus method}

The validity and reliability of consensus methods are conditioned by the composition of the expert panel. The final consensus reflects the position of the experts who participated in the discussion. ${ }^{27}$ For this consensus method, we chose to set up a panel for which the expertise was oriented towards the same fields (occupational health and perinatal health) by varying the "professional profiles' (professions and sectors of activity). Such heterogeneity was chosen to avoid the automatic convergence of opinions and to vary the points of view.

\section{Perspectives}

Improving the impact of the occupational physician's decisions

The relative risks related to biomechanical and organisational constraints are low, generally between 1 and 1.5 and rarely exceeding 2 . However, as the number of working pregnant women increases, ${ }^{48}$ a number of complications could probably be avoided if these factors were considered. In summary, although the relative risks are relatively low, the attributable risks may become significant given the high prevalence of exposure. Croteau ${ }^{21}$ introduced the notion of the 'number of pregnant workers to be subtracted from exposure to avoid one case': for women exposed to at least four types of occupational exposure, the removal of 14 from the workplace would make it possible to avoid one case of premature delivery (this number rises to 33 for 3 constraints, 49 for 2 constraints and 80 for 1 constraint). Reducing or eliminating physical and/or psychological 'stress', particularly when it occurs in the third trimester of pregnancy, would lead to an improvement in the fetal prognosis in terms of birth weight and term at delivery. ${ }^{19}$

The decisions of the occupational physician could therefore have a true impact on public health. The variability of occupational health practices weakens this potential impact, which could be strengthened by improving the identification of risks and the characterisation of exposure by developing research on these issues.

Improving the identification of risks by the occupational physician In France, the only compulsory occupational health visits during pregnancy are those required to return after maternity leave. An employee who is pregnant (or plan to become pregnant) is not necessarily referred to an 
occupational health professional during her pregnancy. Thus, risk management is often late or even non-existent.

We previously ${ }^{9}$ stated (in 2019) the steps to be taken by the occupational physician concerning the management of reproductive risks. His/her action should begin by identifying the type of exposure (identification of the hazard and evaluation of the degree of exposure of the employee) and the jobs/tasks for which there is exposure. $\mathrm{He} /$ she should control the risk (by following the main principles of chemical risk prevention, eg). Finally, employees of childbearing age and employers should be informed both of the presence of a risk (residual or accidental) and the need to contact the occupational health service as soon as they wish to become pregnant and even more so as soon as they become aware of the pregnancy.

By proposing exposure thresholds, the results of this research could help the occupational physician to better identify pregnancy risks related to biomechanical and organisational constraints and target the positions to be adapted.

\section{Improving exposure characterisation}

For most studies, it is difficult to establish precise exposure thresholds because of the difficulty of characterising such exposure. Exposure to biomechanical stress, in particular heavy lifting, illustrates this difficulty. Many criteria must be considered, such as the weight of the object lifted, its shape, the height of the grip, the distance of the grip (far away from the arms or close to the trunk), the asymmetry of the grip (one or two-handed grip), the rotation or anteflexion of the trunk, the duration of lifting, the hourly load, the repetitiveness of the movement, etc. There are an infinite number of situations that make the evaluation of the level of exposure complex. Pregnancy leads to the need to consider additional parameters, such as abdominal volume, the effects of pregnancy-induced ligament laxity, the term of pregnancy, etc.

The same question applies to the other types of exposure studied here. These difficulties are even greater for the question of multiple exposure. The variety of possible associations between constraints, both quantitative and qualitative, makes it impossible to set up studies to evaluate all combinations. The Quebec National Institute for Public Health proposes approaching this question from the perspective of 'overall workload' using various tools that are not based on the sum of the constraints, such as the level of physical activity or the level of energy expenditure. ${ }^{21}$ In addition to the biomechanical and organisational constraints cited here, biological, physical and psychosocial risks further complicate the notion of multiple exposure.

Finally, their characterisation is often carried out retrospectively, based on declarations, which can lead to significant bias. For the types of exposure studied here, there are no standardised and validated questionnaires for pregnant women that allows a homogeneous evaluation of exposure.
Harmonisation of practices in terms of exposure measurement would allow better comparability of acquired values, more 'statistically robust' results, and better levels of evidence to facilitate decision making by experts drafting recommendations for good practice.

\section{Harmonising occupational health practices}

Occupational health practices relating to the prevention of risks to pregnancy are highly variable. There appears to be a need to harmonise practices such that every employee can benefit from the same advice. The example of Quebec provides a possible model, ${ }^{29}$ with the existence of two scientific committees, composed of medical epidemiologists and occupational health physicians who work together to develop medical practice guidelines for occupational physicians. Research and the production of knowledge in occupational health and safety must be promoted to develop solutions adapted to the control of occupational risks. Finally, it is necessary to ensure that such knowledge is properly disseminated to all those involved in occupational health, from the employer to the employee, including the occupational health services.

\section{CONCLUSION}

Several occupational risk factors can increase the risk of pathological pregnancy, including biomechanical and organisational constraints. The increase in risk associated with such exposure is often low to moderate, with relative risks very often less than 1.5 . The characterisation of such exposure is complex and the levels of exposure leading to a significant increase in the risk of pregnancy complications are often unclear. The implementation of a Delphi-type consensus method made it possible to define exposure thresholds that should not be exceeded by pregnant women to assist the occupational physician in his/her risk evaluation. The exposure limits proposed in this study could be considered as common sense reference points for the occupational physician, and not as absolute values to be scrupulously respected. These guidelines could help the occupational health professional to evaluate the risks and the relevance of maintaining an exposed employee at her job, while considering her individual characteristics (medical history, family situation, socioeconomic level, etc) in consultation with pregnancy specialists (obstetricians, midwives, general practitioners). Further studies would be useful to confirm these results and to evaluate the effectiveness of measures to adjust or move the women from the job according to these criteria. Consideration should also be given to harmonising methods of exposure characterisation.

\section{Author affiliations}

${ }^{1}$ Department of Occupational Medicine, University Hospital Centre Bordeaux, Bordeaux, France

${ }^{2}$ Environmental Health Platform Dedicated to Reproduction, ARTEMIS Center, University Hospital Centre Bordeaux, Bordeaux, France

${ }^{3}$ Inserm UMR1219-EPICENE, Bordeaux Population Health Research Centre, Bordeaux, France 
${ }^{4}$ Irset (Institut de recherche en santé, environnement et travail) - UMR_S 1085, IRSET, Rennes, France

Acknowledgements We would like to thank the experts who participated in the consensus method by reading the literature review and answering the questionnaires.

Contributors TC acts as a guarantor, planned the study, collected data, reported results in this paper. RT critically reviewed the study proposal. RG served as scientific advisors, critically reviewed the study proposal. PB served as scientific advisors, critically reviewed the study proposal. GM critically reviewed the study proposal. FD helped collecting data, served as scientific advisors, critically reviewed the study proposal.

Funding The authors have not declared a specific grant for this research from any funding agency in the public, commercial or not-for-profit sectors.

Competing interests None declared.

Patient consent for publication Not applicable.

Provenance and peer review Not commissioned; externally peer reviewed.

Data availability statement Data are available on reasonable request. All data relevant to the study are included in the article or uploaded as online supplemental information. Additional data from this study (literature review data, questionnaire, Delphi results) are available on request from the corresponding author (ORCID ID: 0000-0001-8699-0022).

Supplemental material This content has been supplied by the author(s). It has not been vetted by BMJ Publishing Group Limited (BMJ) and may not have been peer-reviewed. Any opinions or recommendations discussed are solely those of the author(s) and are not endorsed by BMJ. BMJ disclaims all liability and responsibility arising from any reliance placed on the content. Where the content includes any translated material, BMJ does not warrant the accuracy and reliability of the translations (including but not limited to local regulations, clinical guidelines, terminology, drug names and drug dosages), and is not responsible for any error and/or omissions arising from translation and adaptation or otherwise.

Open access This is an open access article distributed in accordance with the Creative Commons Attribution Non Commercial (CC BY-NC 4.0) license, which permits others to distribute, remix, adapt, build upon this work non-commercially, and license their derivative works on different terms, provided the original work is properly cited, appropriate credit is given, any changes made indicated, and the use is non-commercial. See: http://creativecommons.org/licenses/by-nc/4.0/.

ORCID iDs

Thomas Certenais http://orcid.org/0000-0001-8699-0022

Fleur Delva http://orcid.org/0000-0001-5594-5405

\section{REFERENCES}

1 Palmer KT, Bonzini M, Bonde J-PE, et al. Pregnancy: occupational aspects of management: Concise guidance. Clin Med 2013;13:75-9.

2 van Beukering MDM, van Melick MJGJ, Mol BW, et al. Physically demanding work and preterm delivery: a systematic review and meta-analysis. Int Arch Occup Environ Health 2014;87:809-34.

3 Scheftel JM, Elchos BL, Rubin CS, et al. Review of hazards to female reproductive health in veterinary practice. J Am Vet Med Assoc 2017;250:862-72.

4 Palmer KT, Bonzini M, Harris EC, et al. Work activities and risk of prematurity, low birth weight and pre-eclampsia: an updated review with meta-analysis. Occup Environ Med 2013;70:213-22.

5 Carbone P, Granata O, Mantovani A, et al. EUROCAT special report : primary prevention of congenital anomalies in european countries [Internet]. Northern Ireland, 2013. Available: https://eu-rd-platform. jrc.ec.europa.eu/sites/default/files/EUROCAT-Special-ReportPrimary-Preventions-of-CA.pdf [Accessed 21 May 2020].

6 Garlantézec R, Monfort C, Rouget F, et al. Maternal occupational exposure to solvents and congenital malformations: a prospective study in the general population. Occup Environ Med 2009;66:456-63.
7 Sentilhes L, Sénat M-V, Ancel P-Y, et al. Prevention of spontaneous preterm birth: guidelines for clinical practice from the French College of gynaecologists and obstetricians (CNGOF). Eur J Obstet Gynecol Reprod Biol 2017;210:217-24.

8 Delva F, Manangama G, Brochard P, et al. The ARTEMIS center: an environmental health prevention platform dedicated to reproduction. Available: www.mdpi.com/journal/ijerph [Accessed 30 Jun 2020].

9 Certenais T, Manangama G, Coelho J, et al. Exposures to occupational reproductive hazards | Expositions des facteurs de risque sur la reproduction en milieu professionnel. Archives des Maladies Professionnelles et de l'Environnement 2019;80:489-502.

10 French Agency for Food, Environmental and Occupational Health \& Safety. Assessment of the health risks for professionals exposed to atypical working hours, especially night work. ANSES opinion. collective expert report. scientific edition, 2016.

11 van Melick MJGJ, van Beukering MDM, Mol BW, et al. Shift work, long working hours and preterm birth: a systematic review and metaanalysis. Int Arch Occup Environ Health 2014;87:835-49.

12 Bonde JP, Jørgensen KT, Bonzini M, et al. Miscarriage and occupational activity: a systematic review and meta-analysis regarding shift work, working hours, lifting, standing, and physical workload. Scand J Work Environ Health 2013;39:325-34.

13 Bonzini M, Coggon D, Palmer KT. Risk of prematurity, low birthweight and pre-eclampsia in relation to working hours and physical activities: a systematic review. Occup Environ Med 2007;64:228-43.

14 RCP. Physical and shift work during pregnancy: occupational aspects of management. A national guideline, 2009.

15 Lafon D, Abadia G, Basile S, et al. Grossesse et travail. Quels sont les risques pour l'enfant naitre ? Avis d'experts [Internet]. Paris: EDP Scienc, 2010: 568. https://u-bordeaux-scholarvox-com.docelec. u-bordeaux.fr/reader/docid/88802633/page/512?searchterm= Grossesse et travail

16 Hasson F, Keeney S, McKenna H. Research guidelines for the Delphi survey technique. J Adv Nurs 2000;32:1008-15.

17 Jones J, Hunter D. Consensus methods for medical and health services research. BMJ 1995;311:376-80.

18 Specht IO, Hammer PEC, Flachs EM, et al. Night work during pregnancy and preterm birth-A large register-based cohort study. PLoS One 2019;14:e0215748.

19 Katz VL. Work and work-related stress in pregnancy. Clin Obstet Gynecol 2012;55:765-73.

20 Croteau A, Marcoux S, Brisson C. Work activity in pregnancy, preventive measures, and the risk of preterm delivery. $\mathrm{Am} \mathrm{J}$ Epidemiol 2007;166:951-65.

21 Croteau A. Effets de la charge globale de travail sur La grossesse, synthèse systématique avec méta-analyse et méta-régression. Québec, 2015.

22 Croteau A. L'horaire de travail et ses effets sur le résultat de la grossesse. Méta-analyse et méta-régression [Internet]. Québec: Inspq, 2007. https://www.google.com/url?sa=t\&rct=j\&q=\&esrc=s\& source $=$ web\&cd $=1 \&$ ved $=2$ ahUKEwiwiKar-KHhAhUG1BoKHVyoA YgQFjAAegQIARAC\&url=https\%3A\%2F\%2Fwww.inspq.qc.ca\% 2Fpdf\%2Fpublications\%2F677-HoraireTravailGrossesse.pdf\&usg= AOvVaw0AtfiwByHaZCNuzyX-w8ee

23 Schernhammer ES, Rosner B, Willett WC, et al. Epidemiology of urinary melatonin in women and its relation to other hormones and night work. Cancer Epidemiol Biomarkers Prev 2004;13:936-43.

24 Yamauchi H, Iwamoto M, Harada N. Physiological effects of shift work on hospital nurses. J Hum Ergol 2001;30:251-4.

25 Reiter RJ, Tan DX, Korkmaz A, et al. Melatonin and stable circadian rhythms optimize maternal, placental and fetal physiology. Hum Reprod Update 2014;20:293-307.

26 Begtrup LM, Specht IO, Hammer PEC, et al. Night work and miscarriage: a Danish nationwide register-based cohort study. Occup Environ Med 2019;76:302-8.

27 Yousuf M. The Delphi Technique. Essays in Education [Internet], 2007. Available: https://openriver.winona.edu/eie/vol20/iss1/8 [Accessed 26 Jun 2020].

28 Laughlin L. Maternity Leave and Employment Patterns of First-Time Mothers: 1961-2008 Current Population Reports [Internet], 2011. Available: www.census.gov/population [Accessed 05 Dec 2020].

29 Groupe scientifique maternité et travail - INSPQ [Internet]. Available: https://www.inspq.qc.ca/maternite-et-travail/groupe-scientifiquematernite-et-travail [Accessed 03 Jul 2020]. 